Erratum

\title{
Erratum: Actin-binding protein alpha-actinin 4 (ACTN4) is a transcriptional co-activator of RelA/p65 sub-unit of NF-kB
}

\author{
Vasilisa Aksenova1,2, Lidia Turoverova1, Mikhail Khotin', Karl-Eric Magnusson ${ }^{3}$, \\ Eugene Tulchinsky ${ }^{4}$, Gerry Melino ${ }^{2,5}$, George P. Pinaev ${ }^{1}$, Nickolai Barlev ${ }^{1,2,6}$, and \\ Dmitri Tentler ${ }^{1,2}$ \\ ${ }^{1}$ Institute of Cytology, Russian Academy of Sciences, Tikhoretsky av., 4, St. Petersburg, Russia \\ ${ }^{2}$ Laboratory of Molecular Pharmacology, Saint-Petersburg Technological Institute, 26 Moskovsky Prospect, St. Petersburg, \\ Russia \\ 3 Division of Medical Microbiology, Department of Clinical and Experimental Medicine, Linköping University, SE-581 85 \\ Linköping, Sweden \\ ${ }^{4}$ Department of Cancer Studies and Molecular Medicine, University of Leicester, RKCSB, LRI, Leicester, UK \\ ${ }^{5}$ MRC Toxicology Unit, Leicester, UK \\ ${ }^{6}$ Department of Biochemistry, University of Leicester, Lancaster Road, Leicester, UK \\ Published: September 28, 2018
}

Copyright: Aksenova et al. This is an open-access article distributed under the terms of the Creative Commons Attribution License 3.0 (CC BY 3.0), which permits unrestricted use, distribution, and reproduction in any medium, provided the original author and source are credited.

This article has been corrected: During production, the ending page number for this article was listed incorrectly. The page count has now been adjusted to show the proper pagination.

Original article: Oncotarget. 2012; 4:362-372. https://doi.org/10.18632/oncotarget.901 